\title{
CHANGE AND CONTINUITY IN THE COTTAGE HOSPITALS c. 1859-1948: THE EXPERIENCE IN EAST ANGLIA
}

by

\section{STEVEN CHERRY*}

In studies of health care provision prior to the establishment of the NHS the development and contribution of cottage hospitals has been neglected. Because they largely emulated the voluntary general hospitals erected in most major towns by the mid nineteenth century, cottage hospitals have been seen as providers of a basic service in the smaller towns and rural areas, or as "auxiliary hospitals". ${ }^{1}$ While the former description implies a longer term, if minor, tradition, the latter conjures up images of an institution pressed into service, like the wooden hutted accommodation added to the voluntary hospitals in World War I or the ex-poor law infirmaries used to accommodate post-operative cases in World War II. In fact, the proponents of cottage hospitals presented a powerful case, reflected in a wave of hospital building in the last four decades of the nineteenth century. At the time this was well publicized, but the twentieth century record is much less detailed. ${ }^{2}$ A new study by Dr Emrys-Roberts focuses upon the cottage hospitals and restates the case for such local facilities whether as cottage hospital, GP hospital or community hospital. ${ }^{3}$ It emphasizes continuity, for more than half of the original institutions have the same or a similar role today. ${ }^{4}$ Some have been lost, but others have grown into district hospitals and F. B. Smith has suggested that these "shed much of their homeliness and became miniature general hospitals, embryos of what most of them are now."

In examining the role of cottage hospitals this article considers their establishment and characteristics before providing a more detailed analysis of those in East Anglia,

\footnotetext{
* Steven Cherry, Ph.D., Lecturer in Economic and Social History, Centre for Health Policy Research,
} University of East Anglia, Norwich NR4 7TJ.

I am grateful to the Study Leave Committee at UEA for allowing me the opportunity to concentrate on research into hospitals and other health provision in East Anglia.

\footnotetext{
${ }^{1}$ Sir Arthur Newsholme, Medicine and the state, London, George Allen and Unwin, 1932, p. 93.

${ }^{2}$ See B. Abel Smith, The hospitals, London, Heinemann, 1964, pp. 102-6. The most detailed contemporary source is H. C. Burdett, Cottage hospitals, fever and convalescent, London, The Scientific Press Ltd., 1896 and a more recent account is R. M. S. McGonaghey, 'The evolution of the cottage hospital', Medical History, 1967, 11: 128-40.

${ }^{3}$ Meyrick Emrys-Roberts, The cottage hospitals 1859-1990, Motcombe, Tern Publications, 1991.

${ }^{4}$ Ibid, p. 207.

${ }^{5}$ F. B. Smith, The people's health, 1830-1910, London, Croom Helm, 1979, p. 278.
} 
particularly Norfolk and Suffolk, in the first half of the twentieth century. ${ }^{6}$ This area and period are perhaps less thoroughly dealt with than others in Emrys-Roberts' study and it is suggested that the role of the hospitals, their organizational principles and patients all changed to some extent. There was, however, no universal, linear path of development, and growth or the transition to district general hospital status were not necessarily the criteria which defined a "successful" institution. The main sources used are the hospitals' own Management Committee Minute Books and published Annual Reports. A broader view is also obtained from the reports of what became the Norfolk Hospitals Contributors Association (NHCA) in 1939, the eastern area component of the Ministry of Health Hospital Survey undertaken from 1941 and published in 1945, and the initial surveys made by hospital boards under the NHS. $^{7}$

\section{ESTABLISHMENT AND EARLY CHARACTERISTICS}

Arguably the first cottage hospital was established at Shotesham, outside Norwich, by the philanthropic landowner William Fellowes. This may have been as early as 1731 ; it certainly existed by 1754 , for Benjamin Gooch, the leading contemporary East Anglian surgeon in practice at Shotesham, is known then to have used it. ${ }^{8}$ Though the original building survives, it ceased to function as a cottage hospital, probably because it was eclipsed by the founding in 1771 of the Norfolk and Norwich hospital, in which Fellowes and Gooch were critically involved. Over thirty provincial voluntary general hospitals had been established by 1800 and their growth was soon paralleled by the development of specialist institutions in the main population centres. A number of dispensaries were also reconstituted to provide in-patient facilities. In the south west of England a dispensary at Wiveliscombe, Taunton, offered emergency beds as early as 1804 with more permanent arrangements made at Penzance and Teignmouth. ${ }^{9}$ In Norfolk and Suffolk dispensaries in King's Lynn (1812), Great Yarmouth (1822) and Lowestoft (1822) each became voluntary general hospitals before 1840, whilst an eye infirmary and a children's hospital had opened in Norwich by $1853 .{ }^{10}$

The first cottage hospitals with durable qualities were founded in 1859. Cranleigh village hospital, Surrey, represents the model for the small hospital comprising less than a dozen beds, staffed by a GP, in cottage or similar style accommodation. These were initially referred to as "village hospitals" by both Albert Napper, who founded

\footnotetext{
${ }^{6}$ I thank hospital administrators at the Beccles, Cromer and Aylsham (for North Walsham) hospitals for their assistance in enabling me to examine hospital Minute Books and Annual Reports. I am also grateful to staff at the Norfolk Record Office, the Great Yarmouth Central Library and the Norfolk \& Suffolk Hospitals Contributors Association.

${ }^{7}$ Ministry of Health, Hospital survey. The hospital services of the eastern area by Sir William Savage, Sir Claud Frankham and Sir Basil Gibson, London, HMSO, 1945, and Ministry of Health, Hospitals directory, England and Wales, London, HMSO, 1948-9. Appropriate Group references are cited below.

${ }^{8}$ I am indebted to Dr Anthony Batty Shaw, FRCP, for this information. See A. Batty Shaw, 'William Fellowes-"Man of Shotesham", Norfolk Archaeology, 1971, 35, Part II, pp. 183-91 and idem, 'Benjamin Gooch, eighteenth-century Norfolk surgeon', Medical History, 1972, 16: pp. 40-50.

${ }_{9}$ Emrys-Robert, op. cit., note 3 above, pp. $19-20$ and McGonaghey, op. cit., note 2 above, p. 130.

${ }^{10}$ Both the West Norfolk and King's Lynn, and the Lowestoft and North Suffolk hospitals opened in 1836 , followed by the Yarmouth Hospital in 1838. The Norfolk and Norwich Eye Infirmary was established in 1822 and the Jenny Lind Infirmary in 1853.
} 
the Cranleigh hospital, and fellow publicist Horace Swete, who was associated with the short-lived Wrington cottage hospital in Somerset. ${ }^{11}$ Another hospital established in Middlesbrough in 1858 was soon transferred to a prepared site with accommodation for 28 beds at nearby North Ormsby, a larger variation on the cottage hospital theme. By 1875 there were 148 cottage hospitals with a further 146 added in the next twenty years. Information on roughly 60 per cent of these, compiled by $H$. C. Burdett, suggests an average of $15 \cdot 25$ beds per hospital with perhaps 4,500 beds provided in all. ${ }^{12}$ Building continued in the inter-war years with over 600 cottage hospitals providing 10,000 beds by $1934 .^{13}$

Although this growth indicates the perceived utility of cottage hospitals, professional interests and the desire to achieve low cost care largely determined their characteristics. By the third quarter of the nineteenth century the rural or small town general practitioner with some skills in both surgery and medicine had increased in numbers but was rarely allowed to practise in the established voluntary general hospitals. Such honorary work was critical to widening a doctor's reputation and fee-paying clientele. The services of William Cadge, the first surgeon to perform an operation at the Norfolk and Norwich hospital using antiseptic techniques, would be widely sought after and handsomely paid for. ${ }^{14}$ However, the 97 Norfolk practitioners who received a fixed salary or were paid on a case basis as Poor Law Medical Officers in 1858 were much less well rewarded. Norfolk and Suffolk were also strongholds of Friendly Society provision, with 23 per cent of Norfolk practitioners retained by the societies in 1880 and 55 Suffolk doctors associated with a single body, the Ipswich Suffolk County Medical Club. ${ }^{15}$ Such work also involved alleged shortfalls on remuneration and the erosion of clinical control. ${ }^{16}$ In contrast, work in cottage hospitals brought the immediate prospect of additional income from paying patients and a greater proficiency which might later translate into fees from the well-off in the district. ${ }^{17}$ As "a cottage hospital surgeon of eminence" put it, "besides the good to the hospital patients the local surgeon is enabled to 'keep his hand in' at bad accidents and operations, and the rich resident gets the benefit of this in an emergency". 18 The cottage hospital facility also reduced the risk of the GP losing better-off patients to the specialist in the general hospital who, acting firstly as

${ }^{11}$ Edward John Waring, Cottage hospitals, London, John Churchill and Sons, 1867, pp. 2-3. Horace Swete, The handy book of cottage hospitals, London and Weston-Super-Mare, Hamilton, Adams and Co., 1870 .

${ }^{12}$ Burdett, op. cit., note 2 above, p. 32.183 cottage hospitals provided 2,792 beds in 1872 .

${ }_{13}$ Abel Smith, op. cit., note 2 above, p. 408.

${ }^{14}$ Michael Muncaster, 'Medical services and the medical practitioners in Norfolk 1815-1911', Ph.D. thesis, University of East Anglia, 1976, p. 186.

${ }^{15}$ Ibid., p. 76, and H. C. Burdett, Hospitals and charities, London, The Scientific Press, 1914, p. 511.

${ }^{16}$ This was one reason why branches of the BMA often established their own Public Medical Service schemes, as in Norwich. See David Green, Working class patients and the medical establishment, Aldershot, Gower, 1985, p. 12, and C. B. Hawkins, Norwich: a social study, London, Warner, 1910, pp. $278-82$.

${ }^{17}$ McGonaghey, op. cit., note 2 above, p. 138. Himself a former GP with cottage hospital experience, McGonaghey noted "practices in places where there is a cottage hospital have always been more sought after than others and often they command a higher purchase price".

18 "F.R.C.S." cited in Burdett, op. cit., note 2 above, p. 127. Thus "the peasant's misfortune may be the means of saving the life of the squire". 


\section{Steven Cherry}

a consultant, might then be tempted to offer general services on a longer term basis to such patients. ${ }^{19}$

However, broader advantages were also to be gained from the pooling of talents by GPs. In rural areas in the nineteenth century considerations of distance and less intense competition sometimes meant that neighbouring practitioners "attended patients for one another and often cooperated in performing operations". ${ }^{20}$ For example, doctors in Cley, Holt, Hunstanton and Fakenham in North Norfolk made these arrangements in the early $1880 \mathrm{~s}^{21}$ In theory the cottage hospital allowed the extension of this system to all GPs in an area, usually with each acting in turn as the medical officer dealing with emergencies and cases referred by Poor Law Guardians, clergy or charitable agencies. Thus at the Cromer cottage hospital it was "agreed that the doctors should keep charge of the hospital three months in rotation". 22 As "neutral ground" upon which doctors might consult, the cottage hospital could act as a repository for surgical instruments held in common. It was also a store for those medicines and dietary additions which could now be provided on a more adequate and supervised basis than if they featured directly in doctor's charges to patients of limited means at home.

The relatively low cost of cottage hospital treatment was a feature highlighted by proponents from Napper to Burdett. It implied not only efficiency but also the feasibility of a considerable proportion of costs being raised directly from patients. E. J. Waring reckoned that a six bed hospital would be adequate for the needs of a rural population of $4 / 5,000$ and could be established and fitted up in a suitable cottage for as little as $£ 350 .{ }^{23} \mathrm{He}$ also stressed, from the patients' viewpoint, the therapeutic value and convenience of the cottage hospital. Appropriate treatment, rest and diet could be provided without delay and a longer, potentially hazardous journey to the county hospital. Proximity to the "near and dear... homeliness .... and the strictest attention to cleanliness should be the predominant feature ... when a labouring man or mechanic becomes an inmate his surroundings will approximate as near as possible to those of his own humble dwelling". 24 These features, "combined with a certain amount of liberty", exerted "an influence which certainly aids in the recovery of many of the patients", according to the Committee of Management at the Mildenhall cottage hospital. ${ }^{25}$

While the cottage hospitals relied upon the subscriber-recommendation system practised in the larger voluntary general hospitals, they often admitted specific patients to private beds and, characteristically, expected all patients to contribute directly toward costs of treatment and upkeep. This requirement conformed with Victorian beliefs in self-help and also the desires of the BMA that charitable work by doctors should be minimized. ${ }^{26}$ For Burdett, campaigning against "the evils of

\footnotetext{
${ }^{19}$ Abel Smith, op. cit., note 2 above, p. 114-16. This issue was partly resolved via strict demarcation whereby the hospital consultants operated only in that capacity.

${ }^{20}$ M. J. Muncaster, op. cit., note 14 above, p. 172.

21 Ibid., p. 172.

22 Cromer Hospital, Minute Book 1903-25, October, 1907.

${ }^{23}$ Waring, op. cit., note 11 above, p. 25.

24 Ibid., p. 6.

${ }^{25}$ H. G. St. M. Rees, 'A note on the Mildenhall Cottage Hospital', Medical History, 1962, 6: $185-7$.

${ }^{26} \mathrm{See}$, for example, Emrys-Roberts, op. cit., note 3 above, pp. 12-13.
} 
indiscriminate medical relief", still more stringent efforts were required. In 1895 he analysed the details of the ordinary income of 174 cottage hospitals and noted that only 8 per cent of this came from direct patient payments, with 23 per cent from collections, 12 per cent from other donations and 36 per cent from subscriptions. ${ }^{27}$ Nevertheless, the encouragement of voluntary contributions on the part of potential patients, accompanied by donations by the rich to a universally recognized good cause, not only helped hospital finances and channelled income towards the GP but had its additional "class unitary" aspects. ${ }^{28}$ Improving the health of patients was therefore not the only objective served by the cottage hospital system.

\section{THE EXPERIENCE IN EAST ANGLIA}

East Anglia had little overall population growth in the late nineteenth and early twentieth centuries and, apart from the cities, county towns and main ports, its population centres were scattered and small, none exceeding 20,000 before World War II. ${ }^{29}$ Patient catchment areas for the cottage hospitals were clearly defined, though these would overlap with the major hospitals, and any pressure on hospital resources would reflect increasing recourse to hospital facilities rather than population expansion. ${ }^{30}$ The first permanent cottage hospitals in Norfolk were established at Ditchingham in 1865 and Cromer in 1866, while those at Sudbury (1867) and Mildenhall (1868) represent the pioneers in Suffolk. Virtually all the remainder were built by the turn of the twentieth century though later additions included the hospitals at Wells, and Felixstowe and Walton opened in 1910, and at North Walsham, opened in $1924 .^{31}$

At Cromer, Gorleston, Southwold and Thetford, cottage hospitals were set up in converted houses, providing between six and eight beds. In size these were typical of the region, for almost all still had fewer than 15 beds at the close of the nineteenth century, as can be seen from the Appendix. At Beccles and Woodbridge the cottage hospitals developed from dispensaries, the former dating back to 1822 , whilst the hospital at Coltishall was associated with an existing nursing home. But in terms of scale the obvious exceptions were the hospitals at Ditchingham and Halesworth, respectively providing 20 and 29 beds at the outset. "A large, rather rambling one storied building on the pavilion principle", the Ditchingham hospital was built at a cost of $£ 3,000$ and also served as a hospice, run by the Sisters of All Hallows. ${ }^{32}$ Trustees of the Patrick Stead hospital had a $£ 25,000$ legacy at their disposal and were

\footnotetext{
${ }^{27}$ Burdett, op. cit., note 2 above, pp. 6, 35 .

28 Ibid., p. 8.

29 The population of Norfolk declined in the 1890s and the 1930s, while that of Suffolk grew only marginally. In both cases there was migration to the county towns from rural areas.

${ }^{30}$ There was some urban growth (e.g. Felixstowe and Harwich) while coastal resorts (e.g. Cromer) had structural growth and holiday populations.

${ }^{31}$ Others in Norfolk included Swaffham 1888, Thetford 1898, Watton 1899 and Diss 1900. In Suffolk, Beccles 1874, Halesworth 1882, Gorleston 1888, Southwold 1897 and Woodbridge 1861. In Essex, Buckhurst Hill 1865, Hatfield 1867, Saffron Walden 1866, Southend 1881, Braintree and Bocking. In Cambridgeshire, Royston 1870, Wisbech 1873, and Newmarket 1881.

32 Burdett, op. cit., note 2 above, p. 216, and Ditchingham Cottage Hospital, Second Annual Report, Norwich, 1866. The hospital also employed two nurses.
} 


\section{Steven Cherry}

untypically unrestricted in their early planning at Halesworth. ${ }^{33}$ In contrast, the cottage hospitals at Gorleston and Watton were provided at respective costs of just $£ 600$ and $£ 700$, and that at Swaffham struggled into existence as a $£ 400$ memorial to Queen Victoria's Jubilee only after the local vicar had failed in his campaign to spend the money "upon the repairs of the roof of our noble parish church". 34 Wells and District cottage hospital was provided by the Coke family as a memorial to the Second Earl of Leicester in 1910 and primarily intended for tenants of the Holkham estate, whereas workers' collections and Friendly Society contributions financed the Felixstowe and Walton cottage hospital which opened in the same year. ${ }^{35}$

There was considerable variety also in the practical administration of the hospitals. At Cromer, non-medical arrangements were in the hands of a committee of nine ladies, two of whom were titled, with local banking families well represented. Their work included the investigation of patients who were unable to pay for the cost of treatments. Gorleston cottage hospital was controlled by representatives from the local boatmen's companies and Friendly Societies which had helped to establish it. Expenditure at the Rous Memorial hospital, Newmarket was mainly borne by the Jockey Club: stable lads received free treatment, but other residents paid a minimum of $2 / 6 \mathrm{~d}$. per week and private patients were charged two guineas. ${ }^{36}$ Special provision for private patients was not an early characteristic in the hospitals though it was usually made available under the guise of treatment according to the merits of the case, as at Gorleston for those "able and willing to pay the whole or part of the cost". Fixed charges were imposed at Ditchingham and Mildenhall but this practice was less typical than the scale of charges at Cromer or Thetford, where free treatment was provided for the necessitous and "special arrangements" offered to Friendly Societies, Boards of Guardians etc. ${ }^{37}$ Most cottage hospitals relied mainly upon subscriptions and, where these were ample or aided by workplace collections, in-patients were simply invited to contribute towards hospital costs. Thus "patient donations" at Beccles in the early 1900s still amounted to less than 5 per cent of ordinary income, though "annual subscriptions" actually included workplace collections from two local printworks, an engineering concern, railway staff, the Co-op and three Friendly Society lodges. ${ }^{38}$ An annual "shilling subscription scheme" was begun among working people at Gorleston in 1905 and local workplaces undertaking regular collections were allowed to recommend patients from 1910, as was also the case at Felixstowe. ${ }^{39}$ Preceding the National Health Insurance Act of 1911 and the inter-war hospital contributory schemes, these arrangements offered the prospect of steady income for the cottage hospitals, an improved chance of institutional treatment without recourse to the Poor Law or wealthy subscriber for the less well-off and a reduction of the philanthropic effort in GP hospital work.

\footnotetext{
33 J. Newby, The Patrick Stead Hospital, Halesworth, Halesworth, Newby Publicity Organisation, 1964.

${ }^{34}$ Lynn News and Advertiser, 2 July 1887, letter from Rev. Winter.

35 Wells and District Hospital, Annual Report 1929, and A. T. Page, Pennies for health, British Hospitals Contributory Schemes Association, Birmingham 1949, p. 38.

36 Burdett, op. cit., note 15 above, p. 423.

37 Thetford Cottage Hospital, Annual Report, 1895.

38 Beccles Hospital, Report of the Committee of Management, 1902-3.

${ }^{39}$ Gorleston Cottage Hospital, Annual Report, 1905, 1910.
} 
What were the main twentieth century developments? Most obvious were the efforts to extend the scale and quality of cottage hospital services. The nomenclature of the Wisbech and North Cambridge hospital indicated its intended status when it was founded in 1873. With extensions in 1906, it catered for roughly 300 in-patients and 600 out-patients annually by 1912 and its bed provision virtually doubled from 26 to 50 by the mid 1930 s. $^{40}$ As can be seen from the Appendix, there had also been rapid expansion of the hospitals at Southend-on-Sea and Saffron Walden before World War I. At Cromer there was a full transition from the 6 bed cottage hospital to a 38 bed district hospital, rebuilt in 1932 and providing 50 beds by 1947 . Here the surgical staff had a strong reputation, conducting additional operations on child patients for the Norfolk County Council and those in North Norfolk covered by the Norwich Hospitals' Sunday and Saturday Fund Contributory Scheme in the 1920s. Reciprocal links were made with the Norfolk and Norwich hospital under which the Cromer authorities insisted that they should offer more than convalescent, post-operative facilities: "the house was not a cottage hospital . . . they had X-ray apparatus and all operative appliances and major operations were continually being performed". 41 Noting these arrangements the authors of the Ministry of Health Hospital Survey referred to Cromer as "a good little hospital with a great local prestige", interpreting its considerable waiting lists as a sign of confidence in the institution. ${ }^{42}$

Comparable examples from Suffolk were the Felixstowe hospital and St Leonard's, Sudbury. These expanded, respectively from 10 to 34 and 18 to 36 beds between 1911 and 1937, but had also clearly improved their facilities. A good operating theatre and X-ray department were particular features at Felixstowe, while Sudbury was "in all respects . . . as good a cottage hospital as could be found anywhere". 43 The hospitals at Beccles and Gorleston also grew. Each accommodated between 250 and 300 in-patients annually in the 1930s and respectively offered 23 and 26 beds by 1938 . Both had moved to new accommodation, Beccles in 1924 and Gorleston in 1937, and arranged consulting services with Norfolk and Norwich hospital honorary medical staff. Beccles accepted post-operative cases from the Norfolk and Norwich as early as 1922, and performed surgery on patients referred by the Norwich hospitals and the Norfolk and East Suffolk County Councils from $1926 .{ }^{44}$ Ironically, the Beccles and Gorleston hospitals compared favourably with "their" district hospital, the Yarmouth General, in that the latter had failed to develop specialist facilities or consultant services. Gorleston evidently received local preference from patients in the area prior to its relocation as "on many occasions the accommodation was taxed to its utmost. There was frequently a waiting list and urgent cases had to be sent elsewhere as the beds were full". 45

\footnotetext{
${ }^{40}$ Burdett, op. cit., note 15 above, p. 473. Political and Economic Planning, Report on the British Health Services, London, Political and Economic Planning, 1937, Appendix 3. By 1945 there were 65 beds.

${ }^{41}$ Cromer Hospital, Minute Book 1925-29, 1 December 1925. The hospital became Cromer and District Hospital in 1929.

${ }_{42}$ Ministry of Health, op. cit., note 7 above, p. 18.

43 Ibid., p. 16. Felixstowe had 225 in-patients per annum in 1911 and 448 by 1938.

44 Beccles and District War Memorial Hospital, Minute Books 1917-25, 7 March 1921 and 4 December 1922; 1925-43, 4 January 1926 and 6 September 1926.

45 Gorleston op. cit., note 39 above, Annual Report, 1928.
} 
Opening in 1924, the cottage hospital at North Walsham was soon treating 300 in-patients annually and undertaking surgical work on behalf of the Norfolk County Council and the nearby Aylsham Poor Law/Public Assistance infirmary. ${ }^{46}$ By 1930 "the waiting list for major operations" was a cause for concern and additional temporary beds were necessary in 1931. Yet, although it made arrangements to transfer serious cases to the Norfolk and Norwich, the hospital prided itself on the fact that "the great majority of cases requiring treatment have been brought here; very few have gone to Norwich". 47 It saw its future in 1932 in terms of efficiency and quality treatments: "it is not intended to increase the number of beds but to endeavour to keep the whole of the equipment of the hospital thoroughly up to date". 48

None of the remaining institutions examined underwent significant twentiethcentury expansion, again for varying reasons. Although the Patrick Stead hospital had initially ample resources, this and the Ditchingham institution had not subsequently been modernized. Each sometimes referred complex and acute cases, respectively to the East Suffolk and Ipswich or the Norfolk and Norwich hospitals. Nevertheless, the Ministry of Health Hospital Survey suggested that Ditchingham was now inadequate as a cottage hospital and that its role lay "as a home for the chronic sick possessed of some means". 49 Swaffham cottage hospital was also regarded as "thoroughly unsatisfactory" and its closure or complete rebuilding recommended, even though a new wing had been added in 1936 raising the capacity to 20 beds. ${ }^{50}$ Not included in the survey, the Watton hospital was dogged by an inappropriate basic design and an inability to retain and accommodate nursing staff. It was thus falling into disuse by the late 1930s, eventually emulating the Mildenhall hospital which had closed completely in $1932 .{ }^{51}$ Still less fortunate, the 16 bed Aldeburgh cottage hospital was destroyed by bombing in 1942 and temporarily limited to the role of a maternity home in a requisitioned house. ${ }^{52}$ But Southwold cottage hospital was a fully utilized 13 bed institution with definite links with the Norfolk and Norwich. A new out-patients department and operating theatre had been added in the late 1930s, increasing the overall capacity to 20 beds. ${ }^{53}$ And though just eight beds were available at the Wells and District hospital, here too a new operating theatre had been added in 1927 and in-patient numbers almost doubled over the $1920 \mathrm{~s}^{54}$

\footnotetext{
46 North Walsham and District War Memorial Cottage Hospital, Minute Books 1927-31, 1 November 1927 and 22 April 1930.

47 Ibid., 8 December 1931.

48 North Walsham and District War Memorial Cottage Hospital, Annual Report 1932-3, p. 3.

${ }^{49}$ Ministry of Health, op. cit., note 7 above, p. 18.

${ }^{50}$ Ibid., and King's Lynn Area Hospital Management Committee, The first five years 1948-53 (mimeographed, copy in King's Lynn Central Library).

51 Norwich, Lowestoft and Great Yarmouth (Area 6) Hospital Management Committee, First Annual Report 1948-9 (mimeographed, copy in Norfolk and Norwich Hospital Library). Watton cottage hospital temporarily closed in 1950 . The Mildenhall cottage hospital closed primarily because of staffing difficulties and rising costs. See Rees, op. cit., note 25 above, p. 187.

52 Ipswich and East Suffolk Group Hospital Management Committee, An Account of the N.H.S., Ipswich, 1962, p. 100-2.

53 Ibid., pp. 95-7.

54 Wells and District Cottage Hospital, Annual Report, 1929, 1933-5. In-patient numbers rose from an annual average of 90 in the early 1920 s to 155 in the early 1930 s.
} 
UTILITY: TREATMENTS AND ACCESSIBILITY

This outline confirms diverging experiences among the East Anglian cottage hospitals before the 1940 s, with some becoming small district hospitals whilst others slipped back or even closed. Initial size and resources do not seem to have been the critical factor, and population pressure was not a significant feature in explaining the developments which occurred. Nor was expansion the only criterion to be considered in assessing the utility of cottage hospitals. The authors of the hospital survey in the Eastern Region looked for links with a major county or regional hospital, regular evidence of the referral of appropriate cases to specialists and the provision of modern equipment in considering the standard of services which a cottage hospital offered. They also noted strong community support, or indifference, where they encountered it in assessing the future role of such hospitals within a reorganized service. This still left open such issues as the accessibility of the local cottage hospital weighed against the probability of additional facilities at a more distant county general hospital, and whether existing consulting services and referral mechanisms really were made available to poor patients in cottage hospitals as well as those who could afford to pay for them.

Evidence on these questions is scarce and open to interpretation, especially that for the late nineteenth and early twentieth centuries. Some aspects can be considered, however, beginning with the range of treatments available. Ditchingham provides an early example of a cottage hospital with very limited operating theatre facilities. Local doctors did not have open access to it, as they had to await election before they could admit patients, and a consultant surgeon was employed. Private patients and chronic or incurable cases recommended primarily to the care of the Sisters of All Hallows were admitted. The accident cases in 1866 included severe burns, lacerations and fractures and a number of patients suffering from "general debility", dropsy and respiratory complaints. ${ }^{55}$ Surgical cases included the removal of growths, though one such patient was transferred to the Norfolk and Norwich. No in-patient deaths were recorded, although a patient with ulcerated limbs and a "hopeless phthisis case" were discharged incurable. One can only guess at the fate of the patients suffering from "softening of the brain" or "nervous excitement", but, given the fees charged, if these were poorer members of the community their stay in hospital was not likely to be prolonged. There was a greater emphasis on surgery at the smaller Thetford cottage hospital at the turn of the century: 30 of the 80 cases described in two of its early annual reports involved fractures, crushed limbs, concussion or amputations, with additional burns, ulcer and abscess cases. Gangrene and cancers accounted for two each of the recorded deaths and pneumonia the fifth. ${ }^{56}$

Two decades later the ratio of surgical to medical cases at the Gorleston cottage hospital was roughly three to one, and over one third of the 153 in-patients were children. More than 200 accident cases were seen and there was a large number of minor operations, notably for removal of tonsils and adenoids, which comprised the bulk of work done for the local educational authorities. Among the 65 "major"

${ }^{55}$ Ditchingham Cottage Hospital, op. cit., note 32 above.

${ }^{56}$ Thetford Cottage Hospital, Annual Report, 1899, 1905. 


\section{Steven Cherry}

operations, the 16 appendectomies indicated the widening scope of surgery, while mastectomies and hysterectomies represented examples of operations which would not have been contemplated in the later nineteenth century. ${ }^{57}$ The introduction of the panel system under the 1911 act was reflected in a sharp drop in the number of out-patients attending the Beccles hospital, from over 450 annually in the early $1900 \mathrm{~s}$ to roughly 200 in the early 1920 s. $^{58}$ As 80 per cent of these were casualty cases requiring minor surgery it is possible that GPs were treating panel patients in their surgeries while the dependants of such patients, not included in the panel system, applied to the hospital for free or low cost treatments. In new accommodation from 1924, this hospital now had two surgical TB beds funded by Norfolk County Council and this work may have been reflected in the 17 recorded in-patient deaths that year. Four of these involved pneumonia and two peritonitis. The remainder included cases of ruptured appendix, rheumatic endocarditis, diabetic corpora, "fits", compound fracture, a broken back and cancer, with three deaths unspecified and one patient dead on arrival. ${ }^{59}$ At North Walsham, roughly 70 major operations were performed annually in the late 1920s, though here it is unclear whether these included the tonsillectomies performed on "Education Committee" patients. ${ }^{60}$ In the last quarter of 1928 the latter comprised no less than 35 of the hospital's 84 in-patients. Both Beccles and North Walsham additionally received maternity cases involving complications and at Wells natural births, caesarian sections and "incomplete abortions" were all recorded. 61

Where the cottage hospitals provided facilities for local authorities or hospital contributory schemes, their GP surgeons might receive a percentage from the local authority block grant or the contributory scheme allocation to their particular hospital, usually standardized at 20 per cent by the late 1930 s. At each of the hospitals mentioned cases were referred to the Norfolk and Norwich, cancer patients for radium therapy, for example, and indeed the GPs at Beccles insisted upon their right to refer in a dispute with that hospital's Committee of Management in $1937 . .^{62}$ Ambitious surgery was being attempted in the hospitals, usually by GPs but also by visiting consultants who, for instance, performed skin grafts. ${ }^{63}$ Undoubtedly the provision of prompt, basic treatment to a widening range of patients by the second quarter of the twentieth century was a great benefit. But what if the GPs, eager to retain patients and fees, sought to practise at levels beyond their professional competence? Not surprisingly, such accusations were made by specialists in the larger

\footnotetext{
${ }^{57}$ Gorleston Cottage Hospital, Annual Report, 1923, 1926-30. Recorded death rates among in-patients averaged 6 per cent.

58 Beccles and District War Memorial Hospital, Report of the Committee, 1903, 1919-25.

59 Idem, Admissions and Discharge Book, 1924-1938, 1924. One quarter of the in-patients were aged under 14 years.

${ }^{60}$ North Walsham, op. cit., note 46 above, compiled from entries in Minute Book 1929. The Norfolk County Council paid the hospital 11.57 p for each tonsillectomy (22 April 1930). The hospital had appointed specifically an "Honorary Consulting Surgeon for diseases of the ear, nose and throat" (24 July 1928) and an Honorary Consulting Dental Surgeon (11 September 1928). 1928 information cited 11 December 1928.

61 Wells, op. cit., note 54 above, 1933.

62 Beccles, op. cit., note 44 above, 4 January 1937.

${ }^{63}$ Wells, op. cit., note 54 above, 1935.
} 
voluntary general hospitals. These felt that they were now losing consultant fees from what should have been GP-referred patients, whilst they were simultaneously expected to provide the free element of work implicit in their honorary capacity in such institutions. ${ }^{64}$ Nevertheless, there was genuine professional and lay anxiety that the GPs' lack of specialization and over-ambition were contributing to a needlessly wide variation of medical standards and poor surgical work in the cottage hospitals. ${ }^{65}$

Was this always the case? From the detailed study of Norfolk practitioners by M. J. Muncaster it can be suggested that, long before the 1920s, consultants at the Norfolk and Norwich hospital were involved with most, if not all, the cottage hospitals in Norfolk and north-east Suffolk. Thus Swaffham cottage hospital cited Sir Frederick Bateman and William Cadge as consultants. When Cadge died in 1902 he was followed by T. H. Morse, another Norfolk and Norwich consultant with the distinction of being only the second surgeon successfully to close a perforated gastric ulcer. Morse had previously acted as consultant at Watton cottage hospital and continued in this capacity at Cromer, along with A. Burton, previously at Addenbrooke's hospital, Cambridge. The services of these specialists may have been irregular or limited only to wealthy patients but it was not always only the latter who were referred from the cottage to the larger hospital. Late in 1895, H. C. Dent, the Medical Officer at Cromer, trepanned the skull of a labourer, Lawrence Reynolds, who had been shot through the back of the head. The patient was unconscious for three weeks, having "lost at least $1 \mathrm{oz}$. of grey matter" ${ }^{66} \mathrm{He}$ was subsequently referred to the Norfolk and Norwich for what must have been very early usage of the new X-ray facility there, which confirmed the bullet's location in his front orbital plate. Reynolds survived at least to the age of 76 , although with damaged eyesight, leaving the Cromer doctors to wait long for his head, which they had purchased with a view to sectioning in order to follow the track of the bullet!

Reynolds represents a classic "interesting case" in which the cottage hospital GP saved a life, used extant referral mechanisms and the most up to date facility at a larger hospital. Were the procedures described more regularly used in the twentieth century? The improvement of basic facilities at a number of cottage hospitals has already been noted and Dr Emrys-Roberts suggests that "with one dramatic exception (the discovery of X-rays) the advances in medical science were, for those first forty years, relatively gentle ... the cottage hospitals were able to enjoy a period of high summer". ${ }^{67}$ However, with the techniques and range of surgery stimulated by World War I, the growth of specialist clinics and laboratory facilities and the advent of new treatments, for example, the use of radium and sulphonamides, it is likely that the gap between the best voluntary general hospitals and the cottage hospitals had widened by 1940 . While the differences were much less clear in the early 1920 s, official reports from the Cave Committee in June 1921 to the British Hospitals Association

\footnotetext{
${ }^{64}$ Dr Frank Honigsbaum, Health, happiness and security. The creation of the National Health Service, London, Routledge, 1989, pp. 113-14.

65 P.E.P. op. cit., note 40 above, pp. 243, 262.

${ }^{66}$ H. C. Dent, 'Early days of the old Cromer Cottage Hospital', Supplement to the Norfolk Chronicle, 22 July 1932.

${ }^{67}$ Emrys-Roberts, op. cit., note 3 above, p. 153.
} 


\section{Steven Cherry}

Sankey Commission of June 1937 were evidently aware of them. ${ }^{68}$ Their general solution was regional integration, with cottage hospitals acting as satellites around "key" regional hospitals and county or district hospitals. This was seen as a step towards a national hospital service. But, given the traditions of independence in the voluntary hospital sector, the sometimes parochial mentality of cottage hospital authorities and supporters, and the financial concerns of GP medical staffs, even the objective of a regional network was often not attained.

\section{AN INTEGRATED HOSPITAL SER VICE?}

In East Anglia there was progress towards this goal and to the more general use of hospital facilities largely because of the development of hospital contributory schemes. An outgrowth of the pre-1914 system, whereby organizers of workplace or community collections were allowed to recommend cases for treatment in the voluntary hospitals, the schemes usually offered exemption from hospital charges in return for regular contributions of $1 \mathrm{~d}$. or $2 \mathrm{~d}$. per week. ${ }^{69}$ Emergencies apart, suitable cases had to be referred via GPs, a process which screened potential patients and ensured there was not open competition between GPs and hospitals. The extended availability and usage of the GP facility after the implementation of the 1911 National Health Insurance Act raised the possibility of earlier diagnosis, referral and treatment in hospital at low cost and the take-up of hospital contributory scheme membership soon approximated the 1911 GP panel coverage. ${ }^{70}$

For the hospitals these schemes provided an important source of income consistent with attempts to encourage patients to contribute towards treatment costs. It is unlikely that they led to potential funds for the general hospitals being lost, as was often alleged. Rather, the local roots of the cottage hospitals tapped into support which might not otherwise have been forthcoming. Such developments were positively encouraged throughout Norfolk and much of Suffolk by the Norwichbased scheme which offered advice, joint arrangements or full integration to other schemes, as their supporters thought fit. Some cottage hospitals retained independent contributory schemes which lasted until the establishment of the NHS. Those at Beccles and Felixstowe, for example, both dated from 1922 and had respective memberships of 5,150 and 4,000 in $1947 .{ }^{71}$ Others linked their schemes with those of larger neighbours. Swaffham had arrangements with both the Norwich and West Norfolk and King's Lynn schemes from 1926; the Patrick Stead hospital had similar procedures involving the Norwich and East Suffolk and Ipswich hospital schemes after 1930, while the Gorleston cottage hospital merged its scheme with the Yarmouth General's in 1936. North Walsham was unusual in that over 1,000 people were already members of the Norwich-based scheme in 1920 , well before the cottage

\footnotetext{
${ }^{68}$ Ministry of Health, Third Annual Report of the Ministry of Health, London, HMSO, No. 3, 1921-2, p. 27 and P.E.P. op. cit., note 40 above, p. 245.

${ }^{69}$ For discussion of these schemes see Steven Cherry, 'Beyond National Health Insurance: hospital contributory schemes and the voluntary hospitals', J. Soc. Hist. Med., forthcoming.

${ }^{70}$ Ibid. Hospital contributory scheme memberships were the equivalent of roughly two thirds of those covered under the 1911 National Health Insurance arrangements in 1925 and more than three quarters by 1930.

${ }^{71}$ Page, op. cit., note 35 above, pp. 36, 38.
} 
hospital was established, but a jointly organized arrangement was providing more than 40 per cent of the local hospital's income by $1932 .{ }^{72}$ On the other hand, the Committee of Management at Cromer were deaf to early appeals from local trades unions, employers and clergymen and did not finally agree to set up a contributory scheme until $19300^{73}$ Established in conjunction with the Norwich scheme, it covered 52 per cent of all in-patient costs at Cromer by the late 1930s. ${ }^{74}$

However, the adoption of contributory schemes set in motion wider processes. If membership was associated with "free" hospital treatment, why should people in rural areas join the local cottage hospital scheme when a similar contribution might give them access to regional or county hospital facilities? In their own interests, the cottage hospitals thus required some link with a major institution if they were to offer a "more complete" service and prevent potential contributors from joining the county-wide networks of the larger hospitals. They sought reciprocal arrangements under which serious or more complex cases could be transferred to major hospitals while the cottage hospital scheme, rather than the individual concerned, bore the cost. In return, the cottage hospital might provide basic surgical facilities or post-operative care. Thus of the 90 scheme members in North Walsham who received hospital treatments in 1927, 71 were helped at the cottage hospital, 9 were sent to the Norfolk and Norwich, 2 to the Norwich eye hospital, 3 to the Jenny Lind children's hospital and 5 to the Lowestoft convalescent hospital. ${ }^{75}$ This suggests a fair amount of patient mobility under the scheme, as also reflected within cottage hospital wards. Among the 290 in-patients treated at Beccles in 1938-9 were 191 members of the hospital's own contributory scheme, but 31 from other schemes in addition to 30 private patients, a number of accident cases and those "not to be charged" or "dole" patients. ${ }^{76}$

In Norfolk these arrangements were particularly developed because the Norwichbased contributory scheme was only associated with, and not controlled by, the Norfolk and Norwich hospital authorities. The scheme's officers persuaded all voluntary hospitals in the county to standardize in-patient charges at two guineas per week in 1929 and were then able to introduce a voucher system in all associated hospitals. In addition to hospital treatment the voucher covered ambulance and other transport costs, convalescent or rest facilities, and equipment or appliances. ${ }^{77}$ Interchangeability of vouchers in hospitals throughout East Anglia was attained in the mid 1930s and the principle of a common voucher agreed by $1942 .{ }^{78}$ Via such

\footnotetext{
72 North Walsham and District War Memorial Cottage Hospital, Minute Book 1932-36, 19 January 1932. The schemes provided 20 per cent of ordinary hospital income at Gorleston and 35 per cent at Wells by the early 1930 s.

${ }^{73}$ Cromer Hospital, Minute Book 1903-25, 7 December 1920 and 1 August 1922, and 1929-32, 11 February 1930.

${ }^{74}$ Idem., Finance Committee Minutes 1932-39, 16 July 1937.

${ }^{75}$ North Walsham, op. cit., note 46 above, 8 December 1927. A further 44 people received out-patient treatments at the Norfolk and Norwich hospital.

${ }^{76}$ Beccles and District War Memorial Hospital, Admission and Discharge Book, 1938-48, $1938-39$. Twenty were described as accident cases and there were five births.

${ }^{77}$ Norwich Hospitals Contributors Association, Annual Report, Norwich, 1933. Such provision helped to remedy one defect in hospital treatments, the lack of follow-up once patients were discharged.

${ }^{78}$ Arthur Bussey, A century of service, Norwich, Wensum Books, 1974, p. 21.
} 


\section{Steven Cherry}

schemes the cottage hospital patient now had an improved chance of access to more specialized or advanced facilities in larger hospitals. Moreover, the autonomous nature of the Norwich based scheme also allowed cottage hospital authorities to co-operate without sacrificing their independence. This may explain why only the Wells hospital was not fully part of the NHCA county network by 1938 whereas in Suffolk integration into an equally extensive scheme, formally controlled by the East Suffolk and Ipswich hospital, was much less noticeable. ${ }^{79}$ And given the tendency of the NHCA to encourage a range of treatments and services, rather than repetition of basic facilities, this may also explain why populations in towns such as Fakenham were "educated" in the merits of NHCA arrangements rather than in the independent provision of a local cottage hospital.

Ironically, the self-help principles inherent in the contributory schemes may have restricted the growth of private patient facilities in the cottage hospitals. Rooms were usually set aside as private wards for one or two patients and 10-15 per cent of those admitted at the Beccles, Gorleston and North Walsham hospitals paid the three guineas or so per week as private patients in the late 1920 s and 1930s. From 1932, the rebuilt Cromer and District hospital had a private patients block containing six beds and a separate private patients contributory scheme was launched here. ${ }^{80}$ Normally, the hospital contributory schemes restricted membership to those on annual incomes below $£ 250-£ 300$ in the 1920 s and $£ 450$ by World War II. If this limitation was intended to retain wealthy patients for full fees the schemes were certainly seen as a cheaper alternative. Complaints from medical staffs that "some persons who are obviously in receipt of an income exceeding $£ 300$ p.a. are availing themselves of the benefits of the contributory scheme" were not infrequent. ${ }^{81}$ Once vouchers had been introduced it was theoretically possible for a patient to use the voucher to defray two guineas worth of private treatment costs per week and the NHCA did allow this practice, each case being considered on its merits. But payments for this purpose accounted for only 0.5 per cent of NHCA expenditures in the late 1930 s and they were opposed by cottage hospital authorities attempting to guard their allocations of scheme funds. Thus, when the NHCA informed the Beccles hospital that "a Beccles member had applied for a grant towards her fees in the private patients department at the Norfolk and Norwich hospital", it was "resolved that a reply be sent stating that this committee are unable to make a grant". 82 While private patient provision was a feature of the cottage hospitals it had not made inroads into their general contributory schemes. As the latter covered the great majority of county populations in the region by the 1930s their operative procedures had a considerable impact on the hospitals, helping to begin the integration of hospital provision in Norfolk and to a

${ }^{79}$ NHCA membership exceeded 160,000 by 1944 , excluding a separate West Norfolk scheme. The E.S. \& I. scheme had 103,000 members, excluding the separate schemes of the Lowestoft and North Suffolk $(15,700)$, Beccles $(5,150)$ and Felixstowe $(4,000)$ hospitals. West Suffolk was covered by the West Suffolk General $(28,000)$ and Addenbrooke's $(87,500)$ hospitals. Similar schemes at Colchester and North Essex hospital and Wisbech and North Cambridgeshire hospitals had 30,500 and 9,400 members respectively.

${ }^{80}$ Cromer Hospital, Private Wards Insurance Schemes Sub-Committee Minutes, 6 March 1933.

81 See, for example, Beccles and District War Memorial Hospital, Minute Book 1925-43, 3 October 1938.

82 Ibid., 6 February 1939. 
lesser extent in Suffolk which accelerated under the wartime Emergency Medical Service. $^{83}$

However there were obstacles in the way of a co-ordinated hospital service. Admission to hospital under the contributory schemes was not determined by medical need but by the terms of the 1911 National Health Insurance Act, which largely excluded the dependants of contributors from GP services. Some dependants could pay, and the GP was often in a good position to admit a patient at least to the cottage hospital. The rest and the poorest continued to rely upon limited Poor Law/Public Assistance facilities or upon the sympathy of GPs. Local authorities used the voluntary sector to offer hospital treatments for the Schools Medical Service, maternity cases, or TB surgical cases and they could provide for VD cases at the larger voluntary hospitals. But, apart from the odd isolation hospital, they had few institutional medical facilities available in rural East Anglia. Even in Ipswich and Norwich the Public Assistance Infirmaries were poor and not appropriated by the local authorities as public hospitals until 1938 and 1941 respectively. Elsewhere, as the 1945 Hospital Survey noted, " the infirmaries of the PAIs are of a very low standard and no credit to the counties concerned". ${ }^{84}$ It was unrealistic to expect the cottage or general hospitals to atone for this or to play a co-ordinated part alongside a public hospital service which was "except for special purposes practically non-existent" ${ }^{85}$

These failings threw additional responsibilities onto many cottage hospitals as the only institutions offering hospital care in their particular area. They were not keen to publicize any refusal of admission but there were occasional outcries, as in Cromer in 1922 when a Mrs. Parker made such allegations in the Eastern Daily Press. Subsequently two special meetings of the Committee of Management at the hospital insisted that "no case was ever refused through lack of means". ${ }^{86}$ Mrs. Parker does not appear to have been admitted however. The cottage hospital authorities also continued to exercise discretionary powers over in-patients. In the space of a year the North Walsham management committee agreed that in a case of "absolute poverty ... no further steps be taken to obtain payment", while a recovered patient of no fixed abode was transferred to the Aylsham Public Assistance infirmary and a third, John Bates, was discharged as "he had been in hospital for ten weeks". 87

The examples cited above were not unique to cottage hospitals: they arose from inadequate welfare provision in its most general sense and the lack of reasonable accommodation for the chronically ill as well as for the acute sick. In tackling such fundamental problems the role of the cottage hospitals and the disparate views of their authorities were marginal to considerations such as Bevan's overall prescription for a National Health Service, the negotiations with the BMA, or indeed the nationalization of hospitals. As to the cottage hospitals' specific role, general

\footnotetext{
${ }^{83}$ The numbers of members and dependants in the contributory schemes throughout Norfolk and Suffolk were roughly 450,000 and 250,000 in 1947 . These compared with county populations of perhaps 500,000 and 300,000 at that time.

${ }_{84}^{84}$ Ministry of Health, op. cit., note 7 above, p. 6.

${ }^{85}$ P.E.P., op. cit., note 40 above, p. 262.

${ }^{86}$ Cromer Hospital, Minute Book 1903-25, 26 October 1922 and 5 November 1922.

${ }^{87}$ North Walsham, op. cit., note 46 above, Minute Book 1927-31, 1 November 1927 and 18 September 1928.
} 


\section{Steven Cherry}

conclusions are difficult given the variations seen even within a fairly unified area like East Anglia. While Smith's suggestion that most cottage hospitals were transformed into "miniature general hospitals" is broadly correct, some additions are called for. Left to their own devices the cottage hospitals had little in the way of an overall perspective for health services. There were beginnings of links with local authorities often because the cottage hospital was the only practicable provider of certain services. Contributory schemes had a positive impact upon the hospitals' finances and facilities but their other consequences, such as the inclusion of many cottage hospitals in the orbit of larger hospitals, were not necessarily foreseen, still less planned, within the cottage hospitals themselves.

If these changes already affected the cottage hospitals on the eve of World War II, new patterns were imposed under NHS reorganization. Surveys of hospital facilities were repeated in 1948-9 but now with an eye to local health needs and accountability to the taxpayer, or at least the Ministry. What emerged in East Anglia was confirmation of the "key hospital" model and a desire to extend services for the chronically sick within a climate of financial restraint and with the knowledge that there was little in the way of public sector hospital facilities to add to ex-voluntary sector resources for the acute sick. ${ }^{88}$ Given this situation, traditional county boundaries signified little for the grouping of hospitals. The result was a consolidatory approach involving the uprating of "public hospitals" in the cities to link with large voluntary general hospitals, and the closure of small scattered isolation hospitals or their conversion to maternity homes, sanatoria etc. ${ }^{89}$ Most cottage hospitals retained their general role, with GP staffs providing casualty and day to day services, but with special clinics held by consultants operating from the nearest appropriate major hospital. In this way the Rous hospital at Newmarket was formally grouped with Addenbrooke's hospital, Cambridge, Swaffham with the West Norfolk, and King's Lynn and Thetford with the West Suffolk General hospital. ${ }^{90}$ Similarly the Felixstowe and Patrick Stead hospitals were linked with the East Suffolk and Ipswich, but the inclusion of Southwold in this grouping overrode its earlier ties with Norfolk and Norwich. ${ }^{91}$ Gorleston cottage hospital had already amalgamated with Yarmouth General by 1948 and the new sub-grouping was now linked to Norwich. Beccles and Lowestoft made up another, though Beccles retained separate administration as a GP cottage hospital. Finally the Cromer and District hospital was now recognized as central in a North Norfolk group which included the cottage hospitals at Wells and North Walsham. ${ }^{92}$

REORGANIZATION AND ASSESSMENTS: NO ROLE OR A NEW ROLE?

Redrawing the regional hospital map did not alter all the features of its cottage hospitals, some of which could be interpreted as failings. Their domination by GPs

${ }^{88}$ This strategy was outlined in Norwich, Lowestoft, and Great Yarmouth H.M.C., op. cit., note 51 above.

${ }^{89} \mathrm{See}$, for example, Ipswich and East Suffolk H.M.C., op. cit., note 52 above, pp. 66-7.

90 It was recognized that consultant facilities at the West Norfolk and King's Lynn and West Suffolk general hospitals must be improved, as both were mainly staffed by GPs.

${ }_{91}$ Ipswich and East Suffolk became Group Four under the East Anglian Regional Board.

92 To become Group Ten under the East Anglian Regional Board. 


\section{Change and continuity in the cottage hospitals c. 1859-1948}

was seen as a weak point, particularly if this was associated with an exclusive, parochial stance. Dr Frank Honigsbaum's recent study has shown how consultants, in particular Lord Moran, President of the Royal College of Physicians, sought to reduce and ultimately eliminate the direct role of the GP in hospital work.${ }^{93}$ And, as seen, the importance of the consultant was forcefully stated in the 1945 Eastern Region Hospital Survey. Yet most cottage hospitals provided consulting facilities and a few provided clinics. ${ }^{94}$ In this respect they were often no worse and sometimes better than the smaller voluntary general hospitals. It could also be argued that in the best cases the cottage hospital allowed GPs to group and develop sub-specialisms and to overcome their isolation. Here was a potential base for group practice or community health care at a time when the lack of such facilities was being deplored. ${ }^{95}$

A related problem was that the cottage hospital could provide only limited nursing experience, inadequate for the purposes of comprehensive nurse training. The absence of a resident medical officer also placed great responsibilities, particularly in providing immediate attention to casualties, on the matron or nurse left in sole charge of the hospital. This was in the nature of the cottage hospital, yet historically it was perhaps the institution which helped to establish some level of nursing proficiency in more remote areas. There was a time when the matron "sent to a London hospital for three months training", or the regulation that a matron must be "a fully trained nurse with at least six months experience as a ward sister elsewhere", were seen as landmarks in local provision and positive influences on the nursing assistants or the probationary nurses who moved on. ${ }^{96}$

Cottage hospitals were often regarded as inefficient, an allegation which usually derived from the comparison of treatment costs with those of the larger general hospitals, where the range of treatments was more extensive and the level of technology involved was higher. ${ }^{97}$ This might be explained in the less than full utilization of bed capacity, X-ray equipment, operating theatre facilities and so on in hospitals serving smaller communities or scattered populations, all of which would then raise average costs per patient. ${ }^{98}$ Alternative arguments could contrast such efficiency considerations with the values of accessibility, convenience and indeed homeliness which, while impossible to quantify, register strongly with local people.

\footnotetext{
${ }^{93}$ Honigsbaum, op. cit., note 64 above, pp. 113-14, 127

${ }^{94}$ Some of the consultants were "consultoids", but only Thetford and Watton did not use specialists by December 1938 according to the Ministry of Health Survey, op. cit., note 8 above, Appendix One, Table E, p. 33, p. 39. The practice was less frequent in Suffolk and Cambridgeshire. Apart from dental clinics, specialists were holding clinics by this time, for example, at Southwold and North Walsham.

${ }^{95} \mathrm{See}$, for example, P.E.P., op. cit., note 40 above, p. 164.

${ }^{96}$ Dent, op. cit., note 66 above, and Gorleston Cottage Hospital, Rules and Orders (1930 edition), Rule 17. By December 1938 only the Patrick Stead and Watton hospitals employed less than two state registered nurses. The remainder in Norfolk and Suffolk had between two and eight, with generally three or four assistants. See Ministry of Health, op. cit., note 7 above, Table F, p. 33, p. 39.

${ }^{97}$ Such comparisons are hazardous. In 1919/20, for example, weekly in-patient costs were between $£ 3.15$ and $£ 3.30$ at the Lowestoft, Ipswich and Norfolk and Norwich hospitals, but $£ 4.04$ at Cromer. In the late 1920 s such costs were still higher at Cromer (£3.67) than at the Norfolk and Norwich (£2.80), but costs at North Walsham were lower than either (£2.56). But in 1946/7 in-patient costs at Cromer (£7.78) were less than the Norfolk and Norwich $(£ 8.00)$ or North Walsham (£8.90).

${ }_{98}$ Thus in-patients costs were lower at North Walsham in the late 1920s because the hospital there was usually 85 per cent full, whereas Cromer averaged about 60 per cent of its "full" capacity.
} 
The consultants who in 1945 recommended closure of the Swaffham cottage hospital because its operating theatre dated from 1912, without taking into account local efforts to add a new wing to the hospital in 1936 and poor ambulance services to Norwich and King's Lynn, clearly ran the risk of upsetting a "parochial" local community. Immediately after the "appointed day" moves to close cottage hospitals (Watton) or to downgrade them (Ditchingham) could be justified only if they were associated with better replacements or greater utilization of nearby specialist facilities. Such arguments were less convincing when the same source acknowledged that already in the main hospital "all wards and departments are now working to the very fullest extent". 99

In the course of successive NHS reorganizations threats to ex-cottage hospitals have often been countered by stiff resistance, as in the case of Beccles and District War Memorial Hospital in the mid 1970s and Wells and District hospital in the 1980s. More positively, there has been recognition of the value of the local institution in the GP hospitals and Community hospitals which have developed since the early 1960s. In this Dr Emrys-Roberts sees the revival of the cottage hospital tradition, though the fact that such developments occur now as part of integrated and planned facilities is an important additional feature. ${ }^{100}$ How this newer context is to be sustained, given current reforms in the NHS, is a controversial issue. Without wishing to defend a purely parochial outlook, local reluctance to accept the narrowest of "cost efficiency" criteria indicates that, despite changes in nomenclature and patterns of organization, another healthy aspect of the cottage hospital tradition continues.

\footnotetext{
${ }^{99}$ Norwich, Lowestoft, and Great Yarmouth H.M.C., op. cit., note 52 above, p. 4.

${ }^{100}$ Emrys-Roberts, op. cit., note 3 above, pp. 185-209 develops the case as Chairman of the Association of General Practitioner Hospitals. This area is not the focus of the present article, but interested readers should consult General Practitioner Hospitals, Report of a Working Party appointed by the Royal College of General Practitioners, Exeter, R.C.G.P., 1983, which also includes a valuable bibliography. I am grateful to Dr A. Batty Shaw, who served on the Working Party as Observer from the Royal College of Physicians, for drawing my attention to it and kindly providing me with a copy.
} 
Change and continuity in the cottage hospitals c. 1859-1948

APPENDIX

COTTAGE HOSPITALS: BEDS AND IN-PATIENT NUMBERS IN SELECTED YEARS

\begin{tabular}{|c|c|c|c|c|c|c|c|c|c|c|}
\hline $\begin{array}{l}\text { Location of institution, } \\
\text { year of foundation } \\
\text { (and initial bed provision) }\end{array}$ & $\begin{array}{l}1911 \\
\text { beds }\end{array}$ & $\begin{array}{l}12 \\
\text { IPs }\end{array}$ & $\begin{array}{l}\text { early } \\
\text { beds }\end{array}$ & $\begin{array}{l}1920 \mathrm{~s} \\
\text { IPs }\end{array}$ & $\begin{array}{l}c .1930 \\
\text { beds }\end{array}$ & ${ }^{0}$ & $\begin{array}{l}\text { eve } Y \\
\text { beds }\end{array}$ & $\begin{array}{l}\text { NW2 } \\
\text { IPs }\end{array}$ & $\begin{array}{l}1945- \\
\text { beds }\end{array}$ & $\begin{array}{l}-8 \\
\text { IPs }\end{array}$ \\
\hline Aldeburgh & & & & & & & 14 & 68 & 18 & \\
\hline Beccles $1874(9)$ & 15 & 111 & 21 & 191 & 23 & 261 & 22 & 247 & 23 & 352 \\
\hline Coltishall $1881(8)$ & 8 & 46 & 8 & & 13 & & 7 & & & \\
\hline Cromer $1866(6)$ & 19 & 166 & 20 & 255 & 30 & & 38 & 762 & 50 & 1045 \\
\hline Ditchingham 1865 (20) & 20 & 118 & 20 & & 20 & & 23 & 218 & 23 & \\
\hline Felixstowe $1910(10)$ & 10 & 225 & & & & & 34 & 448 & 34 & \\
\hline Gorleston 1888 & 13 & 63 & 13 & 182 & 15 & 299 & 26 & 428 & 26 & \\
\hline Halesworth 1882 (29) & 27 & & 27 & & 27 & 113 & 22 & 128 & 28 & \\
\hline Mildenhall 1868 & 8 & 47 & 8 & & closed & d 1932 & na & na & na & \\
\hline Newmarket 1881 & 15 & 165 & & & & & 21 & 238 & & \\
\hline North Walsham 1924 (18) & na & na & 18 & 200 & & 308 & 17 & 400 & 20 & 408 \\
\hline Royston 1870 & 8 & 35 & & & & & 28 & 327 & & \\
\hline Saffron Walden 1866 & 37 & 189 & & & & & 43 & 750 & & \\
\hline Southend-on-Sea 1888 & 42 & 879 & & & & & & & & \\
\hline Southwold 1897 (13) & 12 & 104 & 13 & & & & 20 & 269 & & \\
\hline Sudbury $1867(14)$ & 18 & 231 & & & & & 34 & 348 & 36 & \\
\hline Swaffham $1888(6)$ & 6 & 39 & 6 & & 6 & 189 & 10 & 250 & 16 & \\
\hline Thetford 1898 (6) & 7 & 109 & 7 & & & & 9 & 89 & 12 & \\
\hline Watton 1899 (6) & 6 & & 6 & & & & 10 & 82 & 10 & 66 \\
\hline Wells $1910(6)$ & 8 & 93 & 8 & & 8 & 175 & 8 & 116 & 8 & \\
\hline Wisbech 1873 & 26 & 296 & & & & & 50 & 956 & 65 & \\
\hline
\end{tabular}

